\title{
Produção de tijolo ecológico com resíduo de Areia Diatomácea
}

\section{Production ecological brick with Diatomaceous Sand}

\author{
1 Renato Yochio Betsuyaku ryochio@hotmail.com \\ 2 Horácio Guimarães Delgado Junior \\ 3 Izabella Christinne Ribeiro pinto Valadão
}

1 Professor do Centro Universitário Geraldo Di Biase ( UGB- Volta Redonda), engenheiro civil consultor e projetista.

2 Professor adjunto da Universidade do Estado do Rio de Janeiro( UERJ - RJ)o, professor do Centro Universitário de Volta Redonda (UNIFOA- Volta Redonda, RJ ), engenheiro civil consultor e projetista de estruturas de diversas empresas.

3 Professora Adjunta e Pesquisadora da Universidade Federal Fluminense (UFF - Niterói, RJ) e do Centro Universitário Geraldo Di Biase (UGB - Volta Redonda, RJ)

\section{Resumo}

A crescente expansão da construção civil com o desenvolvimento de novos materiais e técnicas construtivas e a inserção de resíduos e de materiais renováveis têm sido de suma importância para o desenvolvimento do setor construtivo e manutenção do meio em soluções sustentáveis. O presente projeto visa estudar a viabilidade da utilização de resíduo de areia diatomácea resultante da filtração da cerveja na confecção de eco tijolos ou tijolos ecológicos. Os tijolos ecológicos são constituídos basicamente de uma mistura simples de solo, cimento e água, que são prensados em prensas que podem ser hidráulicas ou manuais. A escolha do solo a ser utilizado é de suma importância na confecção dos tijolos. Énecessário que o solo possua características de granulometria, teor de umidade e índice de plasticidade e liquidez. O solo escolhido foi analisado, peneirado e secado. 0 resíduo da areia diatomácea passou por processos de secagem prévia e uma secagem a $120^{\circ} \mathrm{C}$ no período de $24 \mathrm{~h}$. A dosagem dos elementos foi volumétrica e as amostras foram analisadas nos períodos de 7, 14, 21 e 28 dias para os testes de compressão simples e absorção de água. 0 estudo foi realizado utilizando-se dosagens diferentes dos materiais constituintes, de modo a se obter o desempenho normativo com a utilização de resíduo em sua composição. Todos os resultados obtidos seguem as normas da ABNT. O uso do resíduo da areia diatomácea como material constituinte do tijolo de solo-cimento, usado como elemento estrutural ou de vedação de uma construção foi analisado e obteve-se uma resistência acima de 1,7 MPa, após o período de 28 dias de cura, com absorção média de água abaixo de $22 \%$ nas amostras, o que o qualifica a substituir, sem nenhuma perda, o tijolo convencional.

\section{Palavras chave}

Sustentabilidade; cimento; cerveja; solo-cimento; alvenaria.

\begin{abstract}
The growing expansion of civil construction with the development of new materials and construction techniques, the inclusion of waste and renewable materials has been of paramount importance to the development of the construction industry and maintenance of the environment in sustainable solutions. This project aims to study the feasibility of using the resulting diatomaceous sand beer filtration of waste in the production of eco bricks or ecological bricks. The choice of soil to be used is of paramount importance in the manufacture of bricks, the soil has to have particle size characteristics, moisture content and plasticity and liquidity index, the chosen soil was analyzed, sieved and dried. The residue diatomaceous sand passed through pre-drying processes and drying at $120^{\circ} \mathrm{C}$ in the 24 hour period. The dosing volume was elements and the samples were analyzed at 7, 14, 21 and 28 days for compressive test and water absorption. The study was conducted using dosages of the various constituent materials in order to obtain regulatory performance with the use of waste in composition, all the results obtained following the ABNT. The use of diatomaceous sand residue as a constituent material of the soil cement wall, used as structural element or sealing a construction was analyzed and gave a resistance greater than $1.7 \mathrm{MPa}$ after 28 days of healing, with an average water absorption below $22 \%$ in the samples, which qualifies to replace without any loss conventional brick.
\end{abstract}

\section{Keywords}

Sustainability; cement; beer; soil cement; masonry.

\section{Como você deve citar?}

BETSUYAKU, Renato Yochio; JUNIOR, Horácio Guimarães Delgado; VALADÃO, Izabella Christinne Ribeiro Pinto. Produção de tijolo ecológico com resíduo de areia diatomácea. Cadernos UniFOA, Volta Redonda, n. 34, p. 23-33, ago. 2017. 


\section{INTRODUÇÃO}

Para prover as necessidades do mundo moderno é imprescindível um aumento de produção que contribua para uma maior quantidade de resíduo, que nem sempre têm um destino ecologicamente adequado. 0 reaproveitamento dos resíduos cerâmicos é bastante oportuno, do ponto de vista ambiental, por se tratar um material que, ao ser descartado de forma inadequada na natureza, provoca grandes impactos ao meio ambiente, sabendo-se que a cada três anos um hectare é poluído por eles. Portanto, a recuperação e reciclagem de resíduos têm um grande valor não só econômico como também ambiental. Para que um produto seja aceito no mercado, sem restrições, é necessário conhecer muito bem o seu comportamento físico, químico e potencial de utilização. No caso de resíduo, é preciso avaliar também a possibilidade de impactos que possam ser causados por ocasião do seu beneficiamento. (GRANDE, 2003)

A construção civil é de suma importância na sustentabilidade dos recursos naturais, devido ao grande volume de recursos naturais envolvidos. Dessa forma, a utilização de materiais residuais alternativos na confecção de tijolos se torna indispensável para a redução de custos das construções e diminuição do déficit habitacional do Brasil.

Um dos grandes desafios da construção civil e da sociedade consiste na solução do problema habitacional do Brasil.

Conforme Penha (2007), o investimento em tijolos de solo-cimento reduz os custos em relação a outros tijolos, portanto a fabricação desse material surge como alternativa para construção, principalmente, no meio rural e em pequenas comunidades.

Uma das soluções que podem minimizar esse problema está na utilização do tijolo de solo-cimento. As vantagens desse material são: sua fabricação, uma vez que o consumo de energia aplicada é baixo, pois não utiliza a queima, como nos tijolos convencionais; dispensa o uso de pilares e vigas e formas em construções de pequenas áreas (até $50 \mathrm{~m}^{2}$ ); rapidez e eficiência no assentamento; o acabamento interno pode ser aparente; há redução de resíduos pós-obra, possibilitando também um ambiente mais limpo no canteiro de obras, gerando, com isso, uma redução no custo de material e de mão de obra.

A utilização desse tipo de material agrega valores imprescindíveis, pois sendo uma mistura simples de solo, cimento e água, compactados em prensas, pode-se adicionar materiais residuais de diferentes características, sem alterações significativas. A noção de sustentabilidade incorpora uma clara dimensão social e implica em atender também as necessidades da população menos abastada, outra dimensão ambiental abrangente, uma vez que busca garantir que a satisfação das necessidades de hoje não podem comprometer o meio ambiente e criar dificuldades para as gerações futuras. Nesse sentido, a ideia de desenvolvimento sustentável carrega um forte conteúdo ambiental e um apelo claro à preservação e à recuperação dos ecossistemas e dos recursos naturais. (BUAINAIN,2006)

É importante salientar que o uso de solo-cimento e do solo melhorado com cimento tem mostrado solução técnica e economicamente viável em diversas regiões do país, tendo iniciado no Brasil, em 1935, com a aceleração da construção de estradas (MACEDO, 2004).

A terra diatomácea é um sedimento amorfo, originado a partir de frústulas ou carapaças de organismos unicelulares vegetais, tais como algas microscópicas aquáticas, marinhas e lacustres, normalmente denominada diatomita. A terra diatomácea é um material leve e de baixa massa específica aparente, cuja coloração varia do branco ao cinza escuro. Esse material é constituído por sílica opalina (58 \% até $91 \%$ ) e impurezas. A maioria das diatomáceas apresentam tamanho entre 4 e $500 \mu \mathrm{m}$. As 
propriedades permitem sua aplicação em filtragem, isolante térmico e acústico, cargas, absorventes, material dielétrico, etc. (CANCELLARA, 2015)

A grande vantagem da diatomácea na filtração é sua composição com elementos unicelulares, que são responsáveis pela aglomeração das impurezas menores, retendo o fluxo para tela interna. 0 resíduo de areia diatomácea proveniente da filtração da cerveja encontra-se em estado pastoso, de coloração marrom claro, saturado de resíduos líquidos.

Figura 1 - Resíduo de areia diatomácea

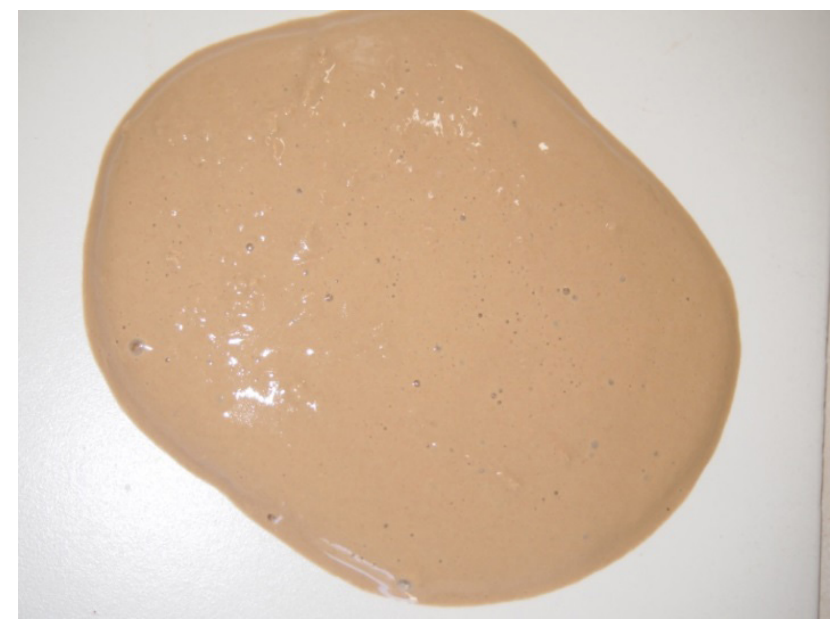

Fonte: dos autores, 2017

Assim, o presente trabalho tem como objetivo demonstrar a execução de tijolos ecológicos com a adição do resíduo de areia diatomácea; relacionar os equipamentos empregados no processo; destacar os cuidados durante as etapas de fabricação, com a finalidade de torná-lo mais economicamente viável e sustentável.

\section{PROCEDIMENTOS EXPERIMENTAIS}

Para o desenvolvimento do presente trabalho foram levantados e analisados as propriedades dos materiais que constituem o tijolo de solo-cimento com adição de resíduo de areia diatomácea, provenientes dos filtros de uma cervejaria, visando à incorporação de materiais residuais na sua concepção e uso como material constituinte na construção civil.

Pode-se utilizar qualquer tipo de cimento para a produção de tijolos, sendo que o mais usado é o cimento Portland comum. A água a ser utilizada no preparo da mistura do solo com o cimento deve ser potável.

Para a execução das amostras o solo escolhido foi de uma área de retaludamento de encosta, situada às margens da Rodovia Lúcio Meira, cimento (CP IV - 32 RS), areia diatomácea (previamente seca e peneirada) e água, misturados com o auxílio de uma betoneira. A água foi incorporada através de um compressor de ar comprimido para facilitar a dispersão da água a obtenção da umidade em toda mistura, tornando-a homogênea e apta para a compactação. 


\subsection{Solo}

A escolha do solo é de suma importância, uma vez que é o material mais importante na confecção dos tijolos A caracterização e escolha do solo segue a sequência descrita na figura 2 . Uma vez definida a amostra, ela deve ser encaminhada ao laboratório de mecânica dos solos, para sua caracterização. Após os ensaios é que se determina a relação que será aplicada na confecção dos tijolos.

\subsection{Fluxograma de caracterização do solo}

Figura 2 - Caracterização do solo

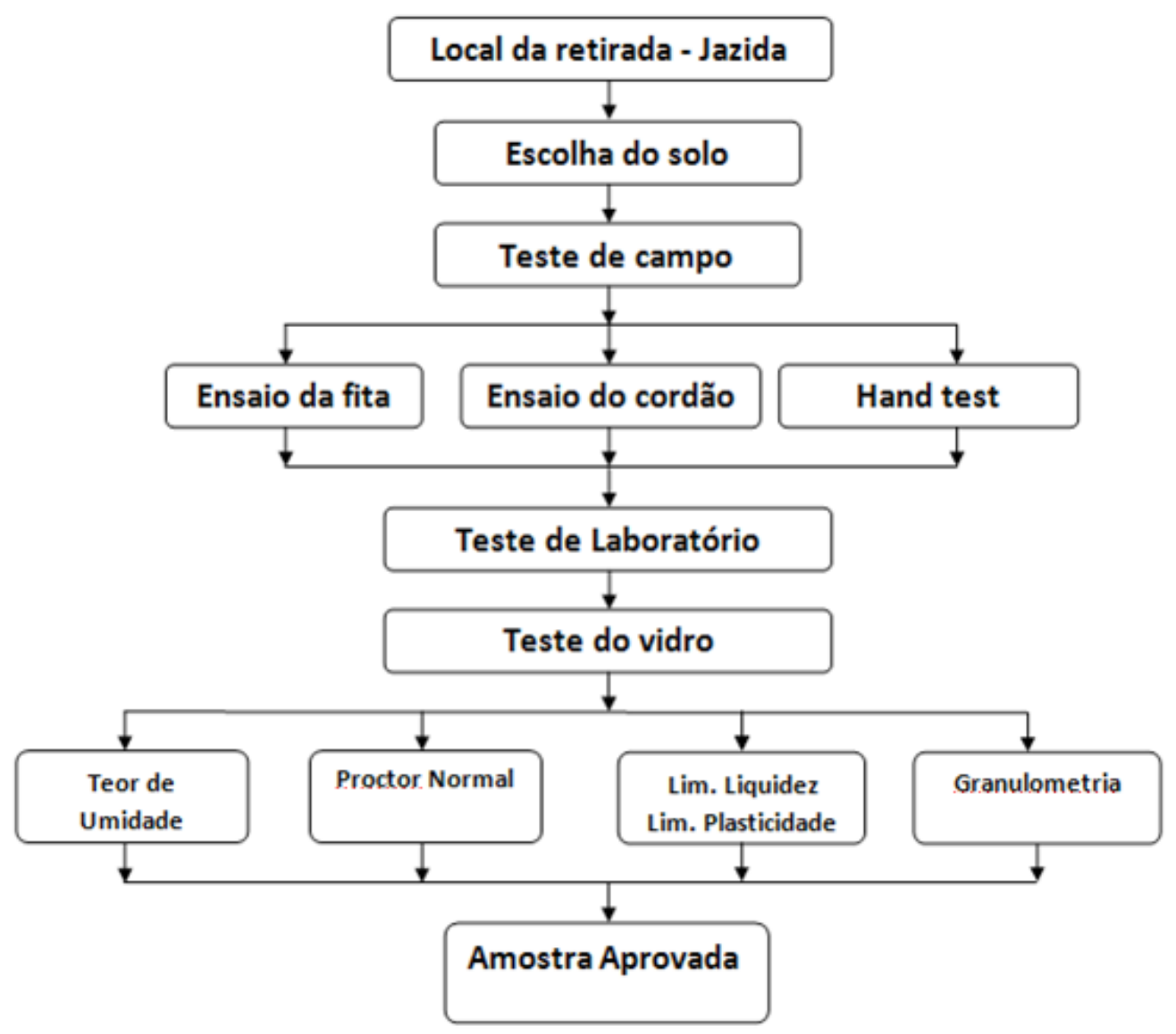

Fonte: dos autores, 2017.

\subsection{Resíduo de Areia Diatomácea}

A produção estimada para o resíduo de areia diatomácea é uma quantidade na ordem de 1,7 Kg/ hl de cerveja fabricada. Nesse caso, o total de resíduo gerado gira em torno de $240975000 \mathrm{~kg} / \mathrm{ano}$ de resíduo úmido. A massa específica seca da areia diatomácea varia de 140 a $200 \mathrm{Kg} / \mathrm{m}^{3}$, enquanto sua massa específica úmida, após sua utilização, está no intervalo de 280 a $340 \mathrm{~kg} / \mathrm{m}^{3}$. O resíduo de areia diatomácea é um excelente filtrante, pois suas características produzem um resultado eficiente e de baixo custo para a indústria cervejeira.

A absorção dos resíduos foi estimada em torno de $80 \%$ de sua massa, sendo que os resíduos foram retirados da amostra através da secagem primária e posterior secagem na estufa pelo período de 24h. 0 resíduo apresenta, de acordo com a bibliografia, uma massa específica aparente de 0,33 g/ 
$\mathrm{cm}^{3}$ e uma massa específica real de $2,36 \mathrm{~g} / \mathrm{cm}^{3}$. A figura 3 mostra os microelementos presentes no resíduo da areia diatomácea responsáveis pela filtração da cerveja.

Figura 3 - Areia diatomácea ampliada 5000x

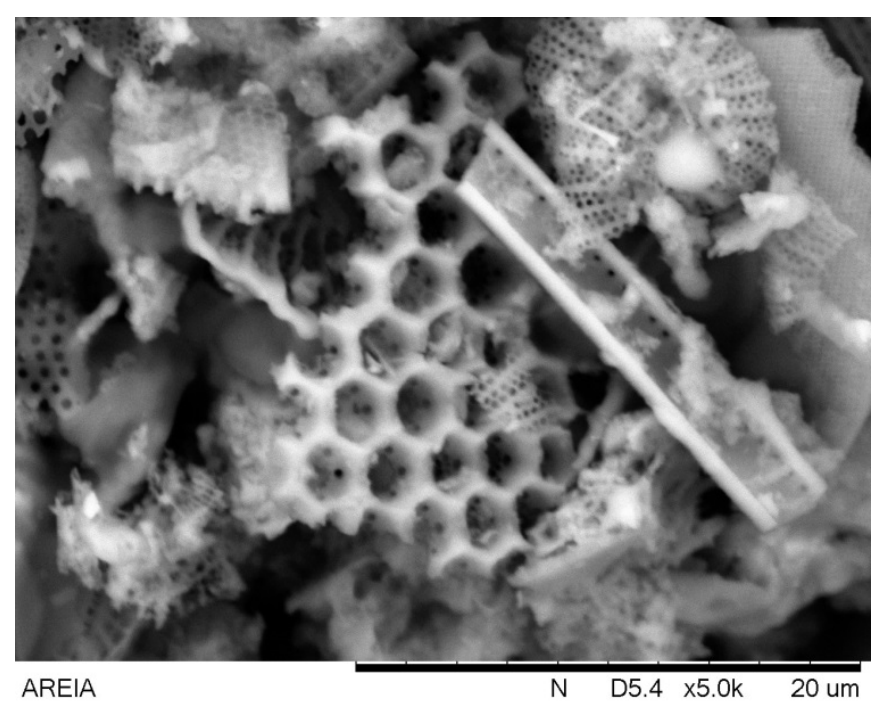

Fonte: dos autores, 2017

A preparação da amostra de areia diatomácea para a confecção dos tijolos segue a sequência descrita na figura 4.

Figura 4 - Resíduo de areia diatomácea

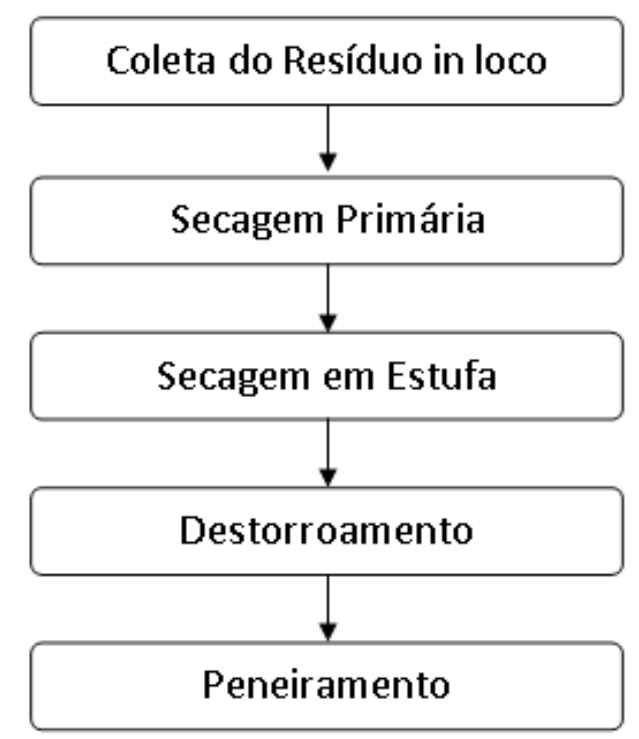

Fonte: dos autores, 2017

\subsection{Fabricação das Amostras}

O tipo de prensa é fator primordial, pois, quanto maior a compactação imposta ao solo, melhor será o desempenho final do tijolo. No mercado, encontram-se diversos tipos de prensas manuais e 
hidráulicas. As últimas imprimem ao solo pressões muito maiores que as manuais, resultando em produtos mais resistentes (BARBOSA 2003).

O procedimento de fabricação do tijolo ecológico com adição de areia diatomácea ocorreu com a utilização da prensa hidráulica ECO PREMIUM 2700, da empresa ECO MÁQUINAS, a qual possui uma caixa carregadora, caixa molde com matriz aquecida e uma parte móvel que realiza a compactação de 6 toneladas. A utilização desse tipo de prensa fornece um produto final com faces lisas e uniformes, com $30 \mathrm{~cm}$ de comprimento e $15 \mathrm{~cm}$ de largura e altura até $7,5 \mathrm{~cm}$. A altura do tijolo é a única dimensão variável, a qual é diretamente proporcional às características do solo e de seu teor de umidade.

Para a confecção das amostras de tijolo de solo-cimento, optou-se por um traço que se considera de boa resistência para a fabricação, sendo de 8:1, ou seja, oito partes de terra para uma parte de cimento. Após a padronização do traço, utilizou-se baldes graduados para a medição dos materiais, sendo que o volume utilizado para cada traço é de 40 litros de solo para cada 5 litros de cimento. (PISANI, 2004)

A sequência construtiva das amostras seguiu os procedimentos descritos na figura 5 .

\subsection{Fluxograma de confecção dos tijolos}

Figura 5 - Confecção dos tijolos

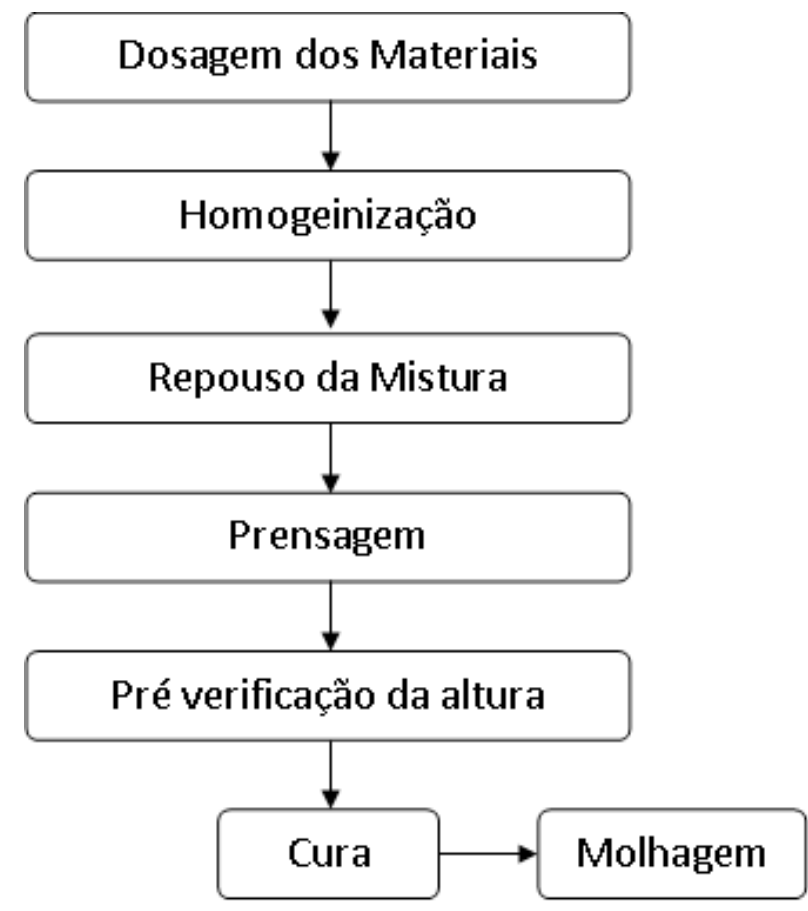

Fonte: dos autores, 2017.

A cura das amostras foi feita por um período de 28 dias necessários para a completa reação do cimento com os elementos da mistura e obtenção da resistência máxima à compressão do tijolo, conforme NBR 10834. Durante esse período, as amostras foram molhadas, inicialmente, nas 6 primeiras horas e, posteriormente, por 7 dias. Durante o processo de cura, deve-se evitar a perda de umidade por evaporação, garantindo uma cura homogênea das amostras. Durante o período de cura, as amostras foram submetidas aos ensaios de absorção de água e de compressão, seguindo a sequência descrita na figura 6. 


\subsection{Ensaios das Amostras}

Figura 6 - Ensaios das amostras

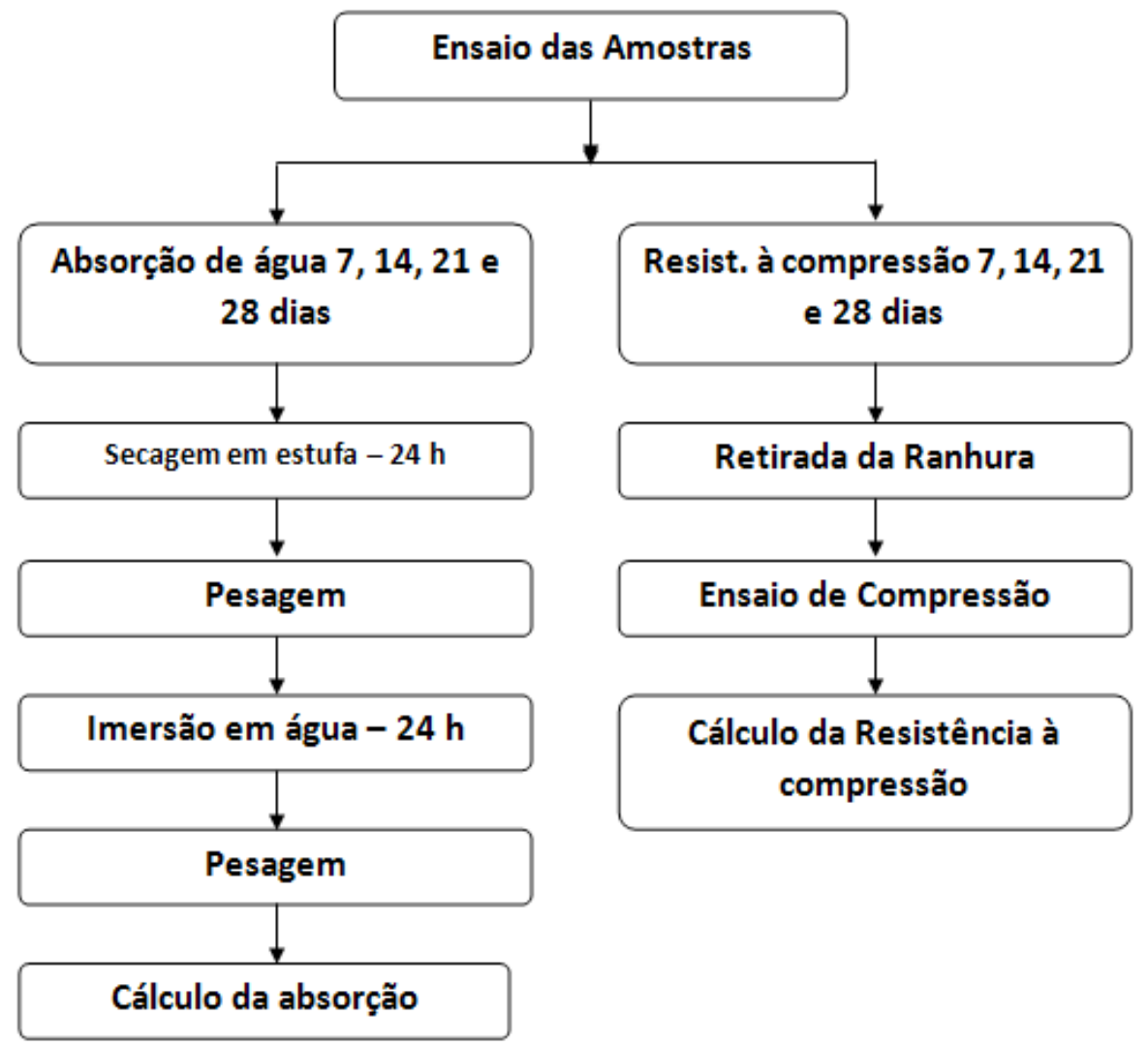

Fonte: dos autores, 2017

A capacidade total de absorção de água se dá pela diferença percentual entre a massa saturada e a massa seca do tijolo, calculada em base seca. As absorções individuais foram obtidas pela equação abaixo, enquanto a absorção média de cada conjunto foi determinada pela média aritmética de 3 repetições.

$$
A=\frac{M 2-M 1}{M 1} .100
$$

M1 - Massa do tijolo seco em estufa (g)

M2 - Massa do tijolo saturado (g)

A - Absorção de água (\%)

Os valores ideais a serem encontrados nesse teste são: máxima de $20 \%$ (média) e $22 \%$ (individualmente). 


\subsection{Ensaios de resistência à compressão.}

Para esse tipo de ensaio foram preparados três corpos de prova para cada ensaio, que foram colocados diretamente sobre o prato inferior da máquina de ensaio à compressão. A seguir, os corpos de prova foram centralizados com ajuda de uma régua graduada.

A face superior não sofreu nenhum tipo de capeamento, pois a prensa utilizada possui uma placa específica de rompimento para blocos. A pressão de compressão, dessa forma, foi aplicada diretamente na face superior do tijolo. A aplicação da carga ocorreu de maneira uniforme e os resultados foram obtidos em Kgf. As cargas foram sendo gradativamente elevadas até ocorrer à ruptura do tijolo.

O resultado final do ensaio foi obtido, dividindo-se a carga máxima de ruptura aplicada pela área da seção transversal das amostras. A resistência média foi obtida a partir da média aritmética das três repetições de cada ensaio. (ROLIM, 1999)

\section{RESULTADOS E DISCUSSÃO}

\subsection{Teste do vidro}

Para esse teste preliminar, os solos mais indicados são aqueles que apresentam as seguintes especificações básicas: teor de areia entre 45 e $90 \%$; teor de silte + argila entre 10 e 55\%; teor de argila menor que $20 \%$. Com base nessa análise preliminar, a amostra de solo escolhida tem as características descritas na tabela 1 e foi destinada a uma análise mais detalhada de suas características granulométricas.

Tabela 1- Caracterização Preliminar

\begin{tabular}{|c|c|c|}
\hline Estimativa de tipo de camada & Altura & \% estimada \\
\hline Arenoso & $11,7 \mathrm{~cm}$ & $65 \%$ \\
\hline Siltoso & $3,5 \mathrm{~cm}$ & $19 \%$ \\
\hline Argiloso & $3,0 \mathrm{~cm}$ & $16 \%$ \\
\hline
\end{tabular}

Fonte: dos autores, 2017.

\subsection{Composição Granulométrica}

A análise granulométrica consiste na determinação do tamanho dos grãos e suas respectivas porcentagens de ocorrência. Essa determinação foi executada, seguindo-se as especificações da norma NBR 7181, bem como os procedimentos do Laboratório de Mecânica dos Solos.

A partir das massas retidas em cada peneira, foram determinadas as porcentagens de solo referentes aos diâmetros das partículas de solo nos peneiramentos grosso e fino. Na sedimentação, a partir das leituras de densidade da solução, estabeleceu-se a porcentagem de solo referente a cada dimensão de partícula, determinando-se a curva granulométrica do material e a classificação do solo utilizado.

Com base na NBR- 7181, determinou-se a porcentagem em peso de partículas representativas da massa total ensaiada e, após os resultados, foi determinada a curva de distribuição granulométrica apresentado na figura 7, com a classificação dos solos. 
Figura 7 - Curva Granulométrica

\section{Curva granulométrica}

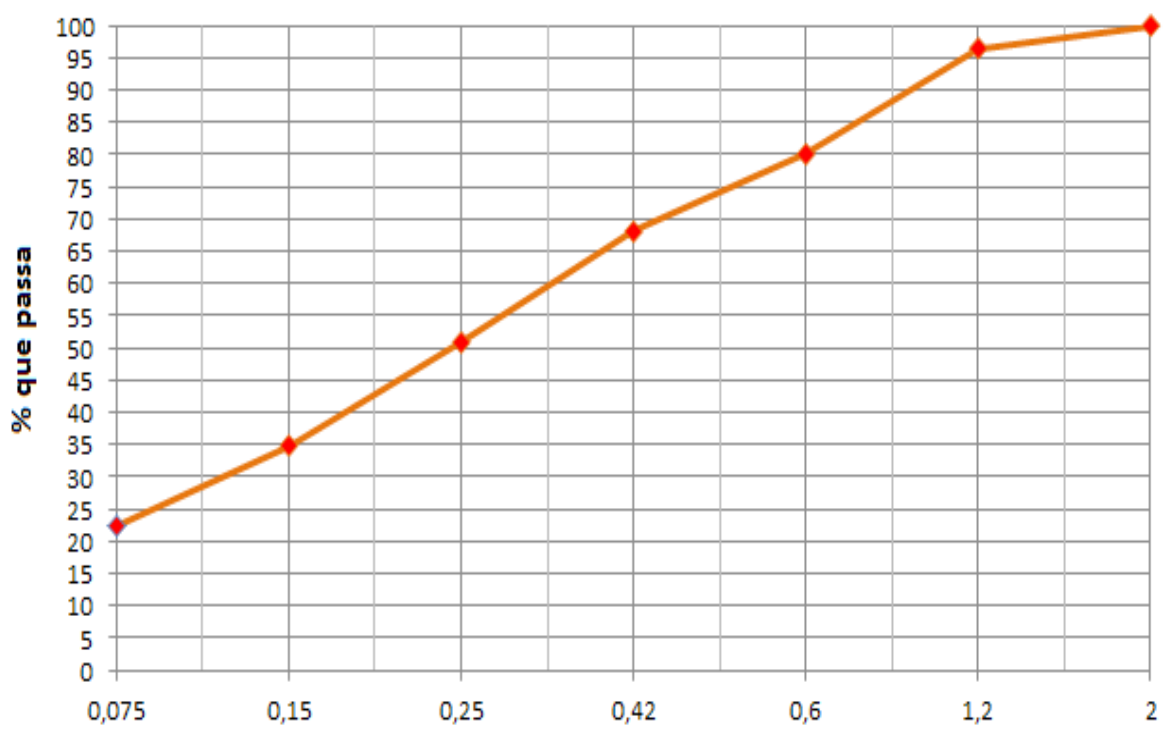

Abertura das peneiras em $\mathrm{mm}$

Fonte: dos autores, 2017

A designação baseia-se nas quantidades percentuais das frações presentes no solo, a partir de $10 \%$. Com a fração dominante primeiramente destacada, o solo em questão é classificado como solo arenoso.

\subsection{Ensaios de resistência à compressão.}

Com base nos resultados obtidos no rompimento dos corpos de prova da amostra padrão, obteve-se um parâmetro de resistência à compressão dos corpos de prova das demais amostras ensaiadas. De acordo com a NBR 10836 os tijolos que apresentarem resistência à compressão aos 28 dias de ensaio superior ou igual a 1,7 Mpa, podem ser utilizados como materiais de alvenaria não estrutural. Uma vez finalizado os testes de compressão na prensa hidráulica, nas amostras T-1 com adição de $10 \%$ de resíduo, em substituição do solo; T-2 com Adição de $5 \%$ de resíduo, em substituição do solo; T-3 com adição de $5 \%$ de resíduo, em substituição ao cimento; e T-4 com adição de $10 \%$ de resíduo, com correção do cimento, as amostras confeccionadas e ensaiadas apresentam um resultado à compressão igual ou superior a mencionada na NBR 10836. Os resultados obtidos nos ensaios estão relacionados na Tabela 2, que apresenta a quantidade relativa de cada material na confecção das amostras, os resultados obtidos nos ensaios de absorção de água e a resistência característica aos 28 dias de cura, após o ensaio de compactação. 
Tabela 2 - Resultados Finais

\begin{tabular}{|c|c|c|c|c|c|c|}
\hline Amostra & Cimento (Litros) & $\begin{array}{c}\text { Solo Argiloso } \\
\text { (Litros) }\end{array}$ & $\begin{array}{c}\text { Areia Diatomác. } \\
\text { (Litros) }\end{array}$ & $\begin{array}{c}\text { Água } \\
\text { (Litros) }\end{array}$ & $\begin{array}{c}\text { Absorção de } \\
\text { água (\%) }\end{array}$ & $\begin{array}{c}\text { Resistência } \\
\mathbf{2 8} \text { dias }\end{array}$ \\
\hline T-1 & 5 & 36 & 4 & 4,7 & $19,93 \%$ & $1,7 \mathrm{MPa}$ \\
\hline T-2 & 5 & 38 & 2 & 5,8 & $20,32 \%$ & $2,3 \mathrm{MPa}$ \\
\hline T-3 & 3 & 8 & 8 & 5,0 & $20,58 \%$ & $2,0 \mathrm{MPa}$ \\
\hline T-4 & 5,5 & 25 & 5 & 5,1 & $20,15 \%$ & $2,1 \mathrm{MPa}$ \\
\hline
\end{tabular}

Fonte: dos autores, 2017.

\section{CONCLUSÃO}

Os ensaios efetuados demonstraram que a adição de areia diatomácea à fabricação de tijolos ecológicos, nas amostras T-1, T-2, T-3 e T-4, apresentaram resultados satisfatórios na sua utilização como material de fechamento não estrutural em substituição à alvenaria convencional, com resistência acima de 1,7 Mpa, conforme recomendado pela norma NBR 10834, após o período de 28 dias de cura. Os resultados dos ensaios de absorção de água unitária e da resistência à compressão dos corpos de prova permitem concluir que o solo-cimento com adição de resíduos de areia diatomácea é uma boa alternativa construtiva, diminuindo-se assim a degradação do meio ambiente e diminuindo-se os custos globais de uma construção. Portanto, a utilização dos resíduos de areia diatomácea na composição dos tijolos ecológicos é uma solução adequada para o meio ambiente e aceitável na conjuntura econômica. 


\section{REFERÊNCIAS}

[1] BARBOSA, Normando P. Estabilização granulométrica de solos para confeç̧ão de tijolos prensados de terra crua. In ENTAC, 8 ${ }^{\circ}$ Salvador, 2000. V. II p. 1043-1050.

[2] BUAINAIN, A. M. Agricultura Familiar, Agroecologia e Desenvolvimento Sustentável: questões para debate. Brasília: IICA, 2006., p.47

[3] CANCELLARA, William R. Introdução à filtração de cervejas Os auxiliares filtrantes. Revista e Portal Meio Filtrante. Disponível em: <http://www.meiofiltrante.com.br/materias>. Acesso em: 01 mai. 2015.

[4] GRANDE, F. M. Fabricação de tijolos modulares de solo-cimento por prensagem manual com e sem adição de sílica ativa. 2003. Dissertação (Mestrado em Arquitetura) - Universidade de São Paulo, São Carlos, 165 p.2003.

[5] MACEDO. Mirtes Maria de. Solos modificados com cimento - efeito no módulo de resiliência e no dimensionamento de pavimentos. Dissertação (mestrado) Universidade Federal de Pernambuco. CTG. Engenharia Civil, 2004.

[6] PENHA, J. R. B.; MOREIRA, G. S. S.; BARATA, M. S. Fabricação de tijolo solo-cimento com substituição parcial do solo natural por resíduo da construção e demolição para construção de casas populares de baixo custo. In: CONGRESSO BRASILEIRO DO CONCRETO, 49, 2007, Bento Gonçalves. Anais. São Paulo: Instituto Brasileiro do Concreto, 16 p., 2007.

[7] PISANI, M.A.J. Execução do tijolo de solo-cimento. Relatório de Pesquisa: Promoção do Desenvolvimento Sustentável do semiárido da Bahia. Universidade Presbiteriana Mackenzie, São Paulo, 2004.

[8] ROLIM, M. M.; FREIRE, W. J.; BERALDO, A. L. Análise comparativa da resistência à compressão simples de corpos de prova, tijolos e painéis de solo-cimento. Revista Brasileira de Engenharia Agrícola e Ambiental, Campina Grande, v. 3, n. 1, p. 89-92, 1999. 